\title{
Usability Evaluation Using Multi-Method for Improvement Interaction in M-Commerce
}

\author{
Daniel Hadrian Yohandy, and *DjokoBudiyanto Setyohadi ${ }^{1,1,}$ \\ ${ }^{1}$ Magister Teknik Informatika, Universitas Atma Jaya Yogyakarta, $55281 \mathrm{Jl}$ Babarsari No. 44, \\ Yogyakarta, Indonesia
}

\begin{abstract}
Today, M-Commerce has become one of the common choices as a way of shopping for society. Therefore, the transaction in $\mathrm{m}$-commerce grows significantly. Moreover, the competition of M-Commerce increases and the performance should be improved primarily for the satisfaction of buyers. These conditions are seen from an improvement of the features and service options that can be used by users, even outside the process of buying and selling goods. Increasing amount of features may reduce the usability of the application which may impact on the performance of MCommerce. Therefore, this study aims to evaluate the usability of MCommerce service. Our study addressed to evaluate the usability of one famous M-Commerce in Indonesia. The evaluation process was performed by using cognitive walkthrough and heuristic usability method. Data collection is done by using depth interview and questionnaire to collect quantitative and qualitative data. Our findings show some new insight for designers and developers about M-Commerce especially about usability and the potential of usability to improving the satisfaction of users in terms of using the M-Commerce application overall.
\end{abstract}

\section{Introduction}

Usability is one of the important factors in a mobile application. Usability is used as a guide to improve the ease of use of using an application, so users can conveniently and easily understand how the application works. Usability assessment is usually done by userevaluation process from the prototype stage to the final product before it is launched in order to guarantee ease of use for everyone [1]. Online shopping through smartphones or $\mathrm{m}$-commerce is the most widely used and continues to grow today due to the characteristics of smartphones which are simple, efficient and high mobility [2].

In addition to the positive impact, smartphones also provide users to easily switch to various other m-commerce. The two aspects that affecting are customer retention and customer attraction owned by a m-commerce [3]. Therefore $\mathrm{m}$-commerce does not far from the effort to increase usability [4] in order to improve customer retention through increased comfort and user satisfaction [5]. Some aspects related to user satisfaction are interaction quality, environment, and output [6].

Good usability will result in user comfort and satisfaction and improve customer retention of $\mathrm{m}$-commerce. Also increased customer retention will have a positive impact on increasing user consumption and directly increase the amount of trading activity and profit

\footnotetext{
${ }^{1}$ Corresponding author: djokobdy@gmail.com
} 
on the m-commerce [7]. Therefore, this research will deepen the experience and opinion from the respondent about usability of the application that support customer retention toward $\mathrm{m}$-commerce $\mathrm{T}$ with an interview about interaction, efficiency, effectiveness, learning, and satisfaction toward m-commerce evaluated [8].

\section{Literature Review}

There have been several previous research related to Cognitive Walkthrough[9][12] and Cognitive Walkthrough was originally developed as an additional tool for evaluation processes in engineering areas, such as giving a preliminary assessment whether users will be in favor to accessing and exploring the system [13]. The goal of the cognitive walkthrough is to assist designers in getting user-side assessments and potentially predicting problems that will arise in the process of interaction with the system [10]. Cognitive Walkthrough also focused on understanding the application learnability for new users by evaluator work through given tasks and answer set of questions [11]. Cognitive walkthroughs can produce deep knowledge from the user's point of view and also help in categorizing and positioning the reasons for the usability problems encountered by respondents.

There have been several previous studies related to usability M-Commerce and various methods applied [13]. One of them is a research on m-commerce in general with a background that $\mathrm{m}$-commerce is more personal than e-commerce. Problems faced are the appearance of issues in the $\mathrm{m}$-commerce application design process are not only from the technical side but also from the end-user point of view which then sought the solution with the evaluation of the respondents [14]. Evaluation of m-commerce usability continues to be profound because m-commerce continues to emerge and develop with its own characteristics to compete in attracting people's attention and trust.

\section{Research Methodology}

This research tries to evaluate the usability of one m-commerce in Indonesia with Cognitive Walkthrough method and assisted by the adoption of the Heuristic method and UPT for data retrieval and processing. The outline of this research (refer to Figure 1) is (1) Scenario Making, 2) Data collection 3) Analysis of evaluation data and analysis of usability problem which then proceed with the conclusion and possible solution to solve usability problems [15].

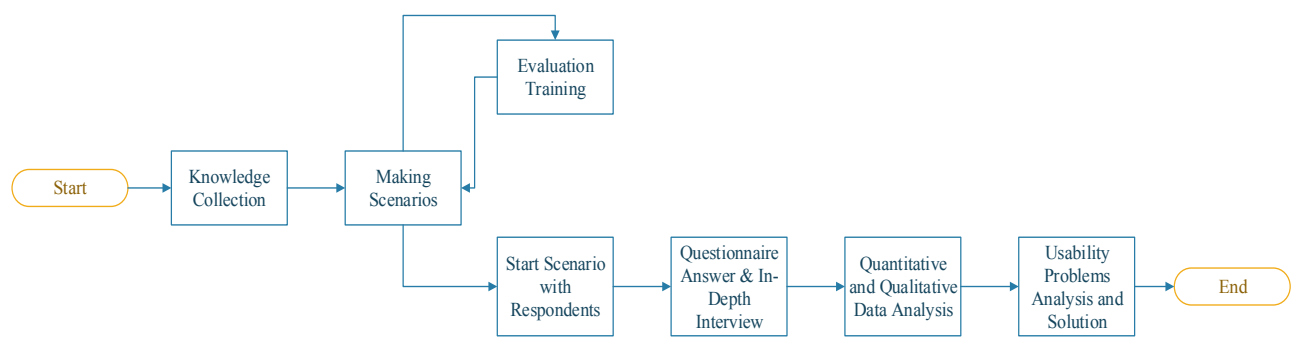

Fig 1. Flow of research

\subsection{Scenarios Development}

Table 1. Heuristic compotation on usability evaluation scenario ( $* \mathrm{~S}=$ Scenario)

\begin{tabular}{|l|l|l|l|l|l|}
\hline Heuristic Usability Elements & S1 & S2 & S3 & S4 & S5 \\
\hline Aesthetic and minimalist design & $\mathbf{x}$ & & & & $\mathbf{x}$ \\
\hline Consistency and Standards & $\mathbf{x}$ & & $\mathbf{x}$ & & \\
\hline Error Prevention & & & & $\mathbf{x}$ & \\
\hline Help users recognize, diagnose, and recover from errors & & & & $\mathbf{x}$ & \\
\hline Help and Documentation & & $\mathbf{x}$ & & & \\
\hline Match between system and the real world & & $\mathbf{x}$ & & & \\
\hline
\end{tabular}




\begin{tabular}{|l|l|l|l|l|l|}
\hline Recognition rather than recall & & & $\mathbf{x}$ & & \\
\hline User Control and Freedom & & & $\mathbf{x}$ & $\mathbf{x}$ & $\mathbf{x}$ \\
\hline Visibility of System Status & & & $\mathbf{x}$ & & $\mathbf{x}$ \\
\hline
\end{tabular}

The scenario development used 9 Heuristic Usability points to be included in five scenarios with the composition shown in Table 1. The heuristic points used are adopted from heuristic points and adapted to the conditions m-commerce selected and nine heuristic usability points [16], [17]. These points cover the interaction that can be done with $\mathrm{m}$ commerce. Scenarios initiated from observation of application interfaces, service trials, evaluation of assistance facilities, product purchasing process, assessment of errors, charging of buyer data, and payment processing [18], [19].

\subsection{Data Collections}

Data collected after the respondent conducted the scenario and performed in 2 ways for 2 data types, the first was the questionnaire for the quantitative data and the second was the interactive interview for the qualitative data. The given questionnaire will ask the respondent's assessment of some elements of the M-Commerce application that attempted when doing tasks in the scenario. In each question in the questionnaire will be provided Likert Scale [20]rating that divided into 5 level consisting of Strongly Agree (SA), Agree (A), Neutral (N), Disagree (D), Strongly Disagree (SD). In the qualitative part, the interview process is done by following the flow of respondents or according to the flow scenario to facilitate the respondent. During the interactive interview process, respondents were invited to issue all opinions about m-commerce usability and accompanied by exploring the reason of the respondents to the problems of reusability encountered.

\subsection{Data Analysis}

Quantitative data from the questionnaire will be processed and calculated mean and standard deviation on 5 scenarios from 10 respondents. For qualitative data will be done several steps to analyze and decode qualitative data into structured data. The following steps will be taken to approach the qualitative data.

\subsubsection{Framework Development}

The initial phase of framework identification is to understand the data collected. Qualitative data obtained from the in-depth interview will be processed with user action data from the video as well as data from the user questionnaire to be aligned and will be processed using the specified framework. This research, leaning toward analysis of qualitative data, therefore, the result will be framed with a table that contains the description of a usability problem, place of occurrence of the problem, and percentage of problem occurrence. Description of the problem of usability is a decoding of raw qualitative data obtained from in-depth interviews with respondents.

\subsubsection{Classification of Usability Problems}

After determining the framework, the next step is to classify the usability problem using the adoption of a predetermined framework which is also followed by giving severity to each reusability problem. To determine the severity, this study will use the categorization of the [21]Travis skeleton. The framework (referred to in Figure 3) uses three main questions, and then the assessment will be given between 1) Low, 2) Medium, 3) Serious and 4) Critical.

\subsubsection{Charting Data}

This step is done by making charts based on the usability problem. The chart will be made based on 3 aspects, namely the classification of the problem of reusability, the occurrence of the problem, and the severity (severity)[22]. 


\section{Result}

All selected are undergraduate and postgraduate students and know about online shopping on the smartphone. Age range of respondents are in 18-29 years and the majority over 20 years. Of the 10 respondents are included 1 who have never done online shopping through $\mathrm{m}$-commerce and 9 of them already doing online shopping through m-commerce. Among those who have been shopping through $\mathrm{m}$-commerce, 5 of them on average purchase 1 item per month, and 4 others on average purchase 2 to 3 items per month. For the type of goods purchased the majority are clothing and electronics. Respondents mostly choose a good transaction process as an important characteristic in a m-commerce.

\subsection{Mean and Standard Deviation Questionnaire Data}

The obtained questionnaire data will be used by calculating the mean and standard deviation (refer to Table 2) of the total of all 10 respondents indicating the UP (Usability Problem). The questions order will be sorted by scenario and assessment of scenario projected by 6 questions for each S (scenario).

Table 2. Mean and Standard Deviation

\begin{tabular}{|l|c|}
\hline Scenario & UP \\
\hline S 1 & 13 \\
\hline S 2 & 10 \\
\hline S 3 & 9 \\
\hline S 4 & 23 \\
\hline S 5 & 6 \\
\hline Mean & 12.2 \\
\hline Std. Dev. & 6.534524 \\
\hline
\end{tabular}

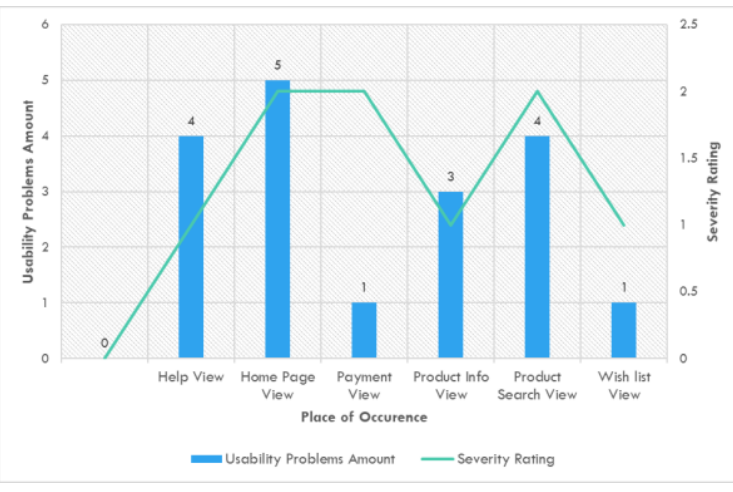

Fig 2. Chart of Usability Problem \& Severity

Chart of usability problem (refer to Figure 2) is describing the location of the incident, the number of usability problems and the severity. This is expected to give a clear picture of the comparison of reusability problems at each location/page in m-commerce applications.

\subsection{Discussion}

There were 90 reusability problems from 10 respondents obtained from the whole method, of which 37 were obtained from the questionnaire and 53 were obtained from the interview. The overall problem of usability is composed into 13 unique usability problems with the percentage requirement in interview method above 30\% that means the problem often encountered by the respondent. Table 3 is list of usability problems based on the percentage of occurrence of the highest problem (preferred method interview), along with the data on the occurrence of the usability problem and severity. Usability issues with the highest percentage are in the help view and product search results view. The help view is not included in the red route in m-commerce applications and only has an average of severity one so that despite having the most complaints from respondents this problem is not critical or critical but needs to be fixed. For product search result page which is the main feature (red route) and the average severity is 2 or medium; therefore, a solution is needed to overcome the problem of found usability. 
Problem with the highest percentage and severity level 2 is about the product suggestion as an alternative in case of problematic search. In interviews, $60 \%$ of respondents felt that they did not get a suitable or desirable product suggestion. Suggested products have different brands and even sometimes different types of products with similarity on the category. In addition to that, the suggested products have little amount therefore indirectly make the user must search again using different keywords to find the desired outcome. This usability problem refers to heuristic points of "Help users recognize, diagnose, and recover from errors".

The issue of usability problems with moderate severity (or 2) with a $40 \%$ percentage occurring on the home page view with a problem of difficulty reaching or finding the desired application function or service on the main page. The home page location is the reason causes a moderate severity because the home page is the main interface in the mobile app to greet users and should be comfortable and not confusing. Then another reusability is that it is difficult to understand the documentation of goods return assistance. From some help to m-commerce main functions, the item return section has a $50 \%$ or high enough reusability problem level even if the severity is only 1 or low.

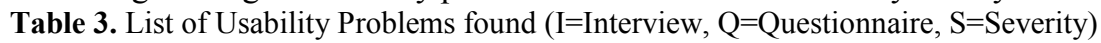

\begin{tabular}{|l|l|c|c|c|}
\hline Usability Problems & Place of Occurrence & \multicolumn{2}{|c|}{ Pct. (\%) } & S \\
\cline { 3 - 4 } & & I & Q & \\
\hline $\begin{array}{l}\text { Difficulty to get suggestions in problematic search } \\
\text { from systems that match the search being performed }\end{array}$ & Product Search View & 60 & 40 & 2 \\
\hline $\begin{array}{l}\text { Difficulty to understand the help regarding the return } \\
\text { of the goods provided by the application. }\end{array}$ & Help View & 50 & 30 & 1 \\
\hline Difficulty to understand the contents of the FAQ & Help View & 40 & 20 & 1 \\
\hline $\begin{array}{l}\text { Difficulty in knowing the wishlist button to add the } \\
\text { product to the wishlist }\end{array}$ & Product Info View & 40 & 20 & 1 \\
\hline $\begin{array}{l}\text { Difficulty reaching or finding the desired application } \\
\text { function or service }\end{array}$ & Home Page View & 40 & 20 & 2 \\
\hline Difficulty finding documentation and help pages & Help View & 30 & 10 & 1 \\
\hline Difficulty finding help for goods return problems & Help View & 30 & - & 1 \\
\hline $\begin{array}{l}\text { Difficulty in finding the desired product in search } \\
\text { view }\end{array}$ & Product Search View & 30 & 10 & 2 \\
\hline $\begin{array}{l}\text { Difficulty understanding the error message on the } \\
\text { problematic search provided by the application }\end{array}$ & Product Search View & 30 & 20 & 2 \\
\hline $\begin{array}{l}\text { Difficulty in knowing the status of the wishlist button } \\
\text { on the selected product }\end{array}$ & Help View & 30 & 20 & 1 \\
\hline Difficulty to choose the preferred payment method. & Payment View & 30 & - & 2 \\
\hline Difficulty to manage the wishlist status of the product & Wishlist View & 30 & 20 & 1 \\
\hline $\begin{array}{l}\text { Difficulty in finding the desired services such as the } \\
\text { contents of the credit or paying the bills }\end{array}$ & Home Page View & 30 & 40 & 2 \\
\hline
\end{tabular}

\section{Discussion\& Conclusion}

Overall, respondents prefer m-commerce applications that provide comfort to users when searching, purchasing goods, and satisfaction after payment because online shopping process ends when the goods are received. Satisfaction resulted by interaction with application can assured the buyer that the order will arrive at the destination without any problems. According to qualitative and quantitative data as support, the problem of reusability problems with the highest percentage occurring on the search results page is the problem of product proposals as a problematic search solution of a system that has a $60 \%$ percentage (moderately high) with moderate severity (or 2) since some respondents may 
overcome searches with other keywords. Another problem with reusable problems with moderate (or 2) severity with a large percentage is the difficulty of reaching or searching for the desired function on the main page.

Based on the results of data analysis, there are three solutions as ideas or suggestions to improve customer retention and customer satisfaction for both new users or old users to remain loyal. The solution includes 1) Create a simple tutorial for the main task process from the main menu to payment. 2) Improve search suggestions or search solutions by adding suggestions generated from each keyword entered so that users can choose. 3) And the addition of structured help documentation with points as a pointer so that users avoid reading all the documentation to find the right solution. For further research, evaluation is expected to be differentiated based on respondent's experience on $\mathrm{m}$ commerce (novice or experienced) so that the usability problem can be categorized to know the priority problem to find the solution in order to improve the usability, convenience, and user satisfaction in online shopping.

\section{References}

1. N. Ahmad, M. W. Boota, A. H. Massom, J. Softw. Eng. Appl. 7, 1045 (2014) https://doi.org/10.4236/jsea.2014.712092

2. R. Agarwal, V. Venkatesh, Inf. Syst. Res 13, 168-186 (2002) https://doi.org/10.1287/isre.13.2.168.84

3. C. Xu, D. Peak, V. Prybutok, Decis. Support Syst. 79, 171 (2015) http://dx.doi.org/10.1016/j.dss.2015.08.008

4. Q. Min, S. Li, Q. Zhong, An Empirical Study of M-Commerce Adoption from Usability Perspective (ICMB, 2009) https://doi.org/10.1109/ICMB.2009.44

5. A. B. Hussain, A. T. Mahmood, R. K. Naser, Investigating the effect of m-commerce design usability on customers' trust (AIP,2017) https://doi.org/10.1063/1.5005410

6. L. Zhao, Y. Lu, L. Zhang, and P. Y. K. Chau, Decis. Support Syst. 52, 645 (2012) http://dx.doi.org/10.1016/j.dss.2011.10.022

7. J. Peng, J. Quan, and S. Zhang, Electron. Commer. Res. Appl. 12, 321 (2013) http://dx.doi.org/10.1016/j.elerap.2013.05.002

8. D. B. Setyohadi, S. Kusrohmaniah, E. Christian, L. T. Dewi, B. P. Sukci, M-Learning Interface Design Based On Emotional Aspect Analysis (IHCI, 2016) https://doi.org/10.1007/978-3-319-52503-7

9. D. Jadhav, G. Bhutkar, V. Mehta, Usability Evaluation of Messenger Applications for Android Phones using Cognitive Walkthrough (APCHI, 2013) https://doi.org/10.1145/2525194.2525202

10. J. Rieman, M. Franzke, D. Redmiles, Usability Evaluation with the Cognitive Walkthrough (CHI, 1995) https://doi.org/10.1145/223355.223735

11. A. Solano, C. A. Collazos, C. Rusu, H. M. Fardoun, Adv. In H.C.I, 2016 (2016) http://dx.doi.org/10.1155/2016/4089520S.

12. S. S. Chan, X. Fang, Y. Zhou, and S. Xu, J. Electron. Commer. Res. 3, 187 (2002) http://citeseerx.ist.psu.edu/viewdoc/summary?doi=10.1.1.85.5067

13. A. Mourouzis, M. Antona, and C. Stephandis, Univers. Access Inf. Soc. 10, 337 (2011) https://link.springer.com/article/10.1007/s10209-010-0211-y

14. A. Hussain, E. O. C. Mkpojiogu, N. H. Jamaludin, S. T. L. Moh, A usability evaluation of Lazada mobile application (AIP, 2017) https://doi.org/10.1063/1.5005392

15. S. L. Keenan, H. R. Hartson, D. G. Kafura, R. S. Schulman, Emp. Soft. Eng 4, 71-104 (1999) https://doi.org/10.1023/A:1009855231530

16. Duggirala, S. (2016, Agustus 17). https://blog.prototypr.io/10-usability-heuristics-withexamples-4a81ada920c 
17. J. Nielsen, R. Molich, Heuristic Evaluation of User Interfaces (CHI, 1990) https://doi.org/10.1145/97243.97281

18. S. Chan, X. Fang, Usability Issues in Mobile Commerce (AMCIS, 2001) http://aisel.aisnet.org/amcis2001/88

19. D. Pinelle, N. Wong, T. Stach, Heuristic Evaluation for Games: Usability Principles for Video Game Design (CHI, 2008) https://doi.org/10.1145/1357054.1357282

20. Likert Scales and Data Analyses. (2007, 7). Retrieved 5 7, 2018, from Quality Progress: http://rube.asq.org/quality-progress/2007/07/statistics/likert-scales-and-dataanalyses.html

21. Travis, D. (2009, 10 5). How to prioritise usability problems. Retrieved 5 7, 2018, from USERFOCUS: https://www.userfocus.co.uk/articles/prioritise.html

22. M. Georgsson, N. Staggers, J. Biomed. Inform. 59, 115 (2016) https://doi.org/10.1016/j.jbi.2015.11.008 